\title{
High-Resolution 7T MR Imaging of the Motor Cortex in Amyotrophic Lateral Sclerosis
}

\author{
(D) M. Cosottini, (D) G. Donatelli, (D) M. Costagli, (DE. Caldarazzo lenco, (DD. Frosini, (DI. Pesaresi, (D) L. Biagi, (D) G. Siciliano, \\ and (D) M. Tosetti

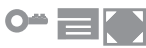

\begin{abstract}
BACKGROUND AND PURPOSE: Amyotrophic lateral sclerosis is a progressive motor neuron disorder that involves degeneration of both upper and lower motor neurons. In patients with amyotrophic lateral sclerosis, pathologic studies and ex vivo high-resolution MR imaging at ultra-high field strength revealed the co-localization of iron and activated microglia distributed in the deep layers of the primary motor cortex. The aims of the study were to measure the cortical thickness and evaluate the distribution of iron-related signal changes in the primary motor cortex of patients with amyotrophic lateral sclerosis as possible in vivo biomarkers of upper motor neuron impairment.
\end{abstract}

MATERIALS AND METHODS: Twenty-two patients with definite amyotrophic lateral sclerosis and 14 healthy subjects underwent a high-resolution 2D multiecho gradient-recalled sequence targeted on the primary motor cortex by using a 7T scanner. Image analysis consisted of the visual evaluation and quantitative measurement of signal intensity and cortical thickness of the primary motor cortex in patients and controls. Qualitative and quantitative MR imaging parameters were correlated with electrophysiologic and laboratory data and with clinical scores.

RESULTS: Ultra-high field MR imaging revealed atrophy and signal hypointensity in the deep layers of the primary motor cortex of patients with amyotrophic lateral sclerosis with a diagnostic accuracy of $71 \%$. Signal hypointensity of the deep layers of the primary motor cortex correlated with upper motor neuron impairment $(r=-0.47 ; P<.001)$ and with disease progression rate $(r=-0.60 ; P=.009)$.

CONCLUSIONS: The combined high spatial resolution and sensitivity to paramagnetic substances of 7T MR imaging demonstrate in vivo signal changes of the cerebral motor cortex that resemble the distribution of activated microglia within the cortex of patients with amyotrophic lateral sclerosis. Cortical thinning and signal hypointensity of the deep layers of the primary motor cortex could constitute a marker of upper motor neuron impairment in patients with amyotrophic lateral sclerosis.

ABBREVIATIONS: ALS = amyotrophic lateral sclerosis; ALSFRS-R = ALS Functional Rating Scale-Revised; DPR = disease progression rate; $\mathrm{HS}=$ healthy subjects; $\mathrm{MI}=$ primary motor cortex; $\mathrm{UHF}=$ ultra-high field; $\mathrm{UMN}=$ upper motor neuron

A myotrophic lateral sclerosis (ALS) is a progressive motor neuron disorder that entails degeneration of both upper and lower motor neurons, ${ }^{1}$ producing fasciculation, muscle wasting and weakness, increased spasticity, and hyperreflexia.

Upper motor neuron (UMN) impairment in ALS can be detected from clinical signs such as brisk reflexes and spasticity; however, the masking effect of the lower motor neuron involvement that reduces muscle strength and reflexes may make it hard

Received June 26, 2015; accepted after revision August 12.

From the Department of Translational Research and New Technologies in Medicine and Surgery (M.Cosottini) and Neurology Unit, Department of Clinical and Experimental Medicine (E.C.I., D.F., G.S.), University of Pisa, Pisa, Italy; Neuroradiology Unit (G.D., I.P.), Department of Diagnostic and Interventional Radiology, Azienda Ospedaliero-Universitaria Pisana, Pisa, Italy; IMAGO7 Foundation (M.Costagli), Pisa, Italy; and IRCCS Stella Maris (L.B., M.T.), Pisa, Italy.

This work is part of the protocol "Clinical Impact of Ultra-High Field MRI in Neurodegenerative Diseases Diagnosis" (RF RF-2009-1546281) approved and funded by the Italian Ministry of Health and cofunded by the Health Service of Tuscany. to reveal clinical evidence of pyramidal involvement. Electrophysiologic investigations, such as prolongation of central motor conduction time in motor-evoked potentials in transcranial magnetic stimulation, may detect the upper motor neuron involvement, but results are conflicting and these measures are not a sensitive tool or a useful indicator of disease severity or prognosis. ${ }^{2-4}$ Therefore, a robust in vivo biomarker of UMN impairment, though desirable, ${ }^{5}$ is not available.

The hallmark of UMN pathology in ALS is depopulation of the Betz cells in the motor cortex and axonal loss within the descend-

\footnotetext{
Please address correspondence to Mirco Cosottini, MD, Via Paradisa 2, 56124 Cisanello, Pisa, Italy; e-mail: mircocosottini@libero.it

- Indicates open access to non-subscribers at www.ajnr.org

$\equiv$ Indicates article with supplemental on-line tables.

Indicates article with supplemental on-line photos.

http://dx.doi.org/10.3174/ajnr.A4562
}

AJNR Am J Neuroradiol 37:455-61 Mar 2016 www.ajnr.org 
ing motor pathway associated with myelin pallor and gliosis of the corticospinal tracts. ${ }^{6}$

Conversely, also, characteristic of ALS pathology similar to that in other neurodegenerative disorders is the occurrence of a neuroinflammatory reaction, consisting of activated glial cells, mainly microglia and astrocytes, and T-cells. ${ }^{7}$ In transgenic mouse models of mutant SOD1-associated familial ALS, reactive microglial cells and astrocytes actively contribute to the death of motor neurons. ${ }^{7}$

Moreover, a significant association between cortical microgliosis and UMN damage has been described by using PET with a radioligand for microglia. ${ }^{8}$

Recently, an ex vivo study with Perls' DAB staining detected intracellular and extracellular iron deposits in the motor cortex of patients with ALS. Iron in the form of ferritin is detected in activated microglia $(\mathrm{CD} 68+)$ in the middle and deep layers of the motor cortex, sparing the superficial layers. ${ }^{9}$

Gradient recalled-echo $\mathrm{T}^{*}{ }^{*}$ sequences, which can provide signal magnitude, phase, and their combination in susceptibilityweighted imaging, ${ }^{10}$ are considered the most appropriate technique to visualize small amounts of uniformly distributed iron, such as ferritin, ${ }^{11,12}$ and are the most sensitive sequences for detecting the low signal intensity in the precentral cortex in patients with ALS. ${ }^{13}$

The introduction of ultra-high field (UHF) MR imaging equipment greatly increases the sensitivity to susceptibility phenomena and allows obtaining in vivo spatial resolution of approximately $200 \mu \mathrm{m}$, which enables determination of the cortical layers. $^{14}$

The aims of our study were to measure the thickness of the primary motor cortex (M1) and to describe the distribution of the iron-related signal changes in the M1 of patients with ALS as a possible in vivo biomarker of UMN impairment by using targeted high-resolution gradient recalled-echo $\mathrm{T} 2{ }^{\star}$ sequences at UHF.

\section{MATERIALS AND METHODS Patients and Controls}

Twenty-two patients (5 women and 17 men; mean age, $61 \pm 10$ years) with a diagnosis of definite ALS (limb onset) according to the revised El Escorial diagnostic criteria ${ }^{15}$ were enrolled (On-line Table 1). Patients with dementia were excluded by administering the Mini-Mental State Examination ${ }^{16}$ and the Frontal Assessment Battery, ${ }^{17}$ as short and rapid bedside tests for a screening of cognitive, behavioral, and global executive dysfunction. Clinical history and standard neurologic and psychiatric assessment were used to rule out possible neuropsychiatric comorbidities and other neurodegenerative diseases.

Patients underwent CSF and plasma laboratory analysis to respectively assess concentration of $\beta$-amyloid, $\tau$, and $p-\tau$ neuronal proteins and some peripheral oxidative stress biomarkers such as advanced oxidation protein products, ferric-reducing ability of plasma, and thiols. ${ }^{18}$ Neurophysiologic investigation included motor-evoked potentials with calculations of central conduction time, cortical latency, and cortical silent period. Disease severity was evaluated by using the ALS Functional Rating Scale-Revised (ALSFRS-R) (range, $0-48),{ }^{19}$ the Medical Research Council scale for segmentary muscle strength (range, $0-130),{ }^{20}$ and a compos- ite semiquantitative arbitrary score of UMN burden (UMN score; range, 0-33) (On-line Table 2). ${ }^{8,21,22}$ Disease duration was expressed in months from symptom appearance to MR imaging acquisition, while disease progression rate (DPR) was calculated according the following formula: (48 - ALSFRS-R)/Disease Duration. $^{23}$

Fourteen right-handed healthy subjects (HS), age-matched with patients ( 8 women and 6 men; mean age, $58 \pm 12$ years), were enrolled to compare the cerebral motor cortex morphology with respect to patients with ALS. HS were volunteers who had no history of psychiatric and neurologic disorders; their neurologic examination findings were normal.

All patients and controls gave their informed consent to the enrollment and diagnostic procedures on the basis of the adherence to an experimental protocol "Clinical Impact of Ultra-High Field MR Imaging in Neurodegenerative Diseases Diagnosis" (RF-2009-1546281) approved and funded by Italian Ministry of Health and cofunded by the Health Service of Tuscany. The study was approved by the local competent ethics committee.

\section{MR Imaging Acquisition}

MR imaging experiments were performed on a 7T MR950 scanner (GE Healthcare, Milwaukee, Wisconsin) equipped with a 2CH-TX/32CH-RX head coil (Nova Medical, Wilmington, Massachusetts).

The MR imaging protocol included a high-resolution 2D multiecho gradient-recalled sequence with $\mathrm{TE}=10 \mathrm{~ms}$ and $20 \mathrm{~ms}$, $\mathrm{TR}=500 \mathrm{~ms}$, flip angle $=15^{\circ}, \mathrm{NEX}=2$, section thickness $=2$ $\mathrm{mm}, \mathrm{FOV}=112 \mathrm{~mm}$, and in-plane resolution $=250 \mu \mathrm{m}$, targeted to the M1, oriented in the axial plane, and covering the cerebrum from the vertex to the internal capsule. The total acquisition time was 7 minutes 32 seconds.

\section{Image Analysis}

Visual Inspection and Subjective Assessment. Two expert neuroradiologists (M.Cosottini and I.P.) blinded to the clinical status of subjects visually evaluated, independently, images on the basis of morphologic criteria.

The M1 in the precentral gyrus was identified on UHF MR images for the presence of the "hand knob." 24 The anatomy of the cerebral motor cortex at the level of the M1 was evaluated on the basis of accepted cognition sourcing from anatomic atlases ${ }^{25}$ and MR imaging studies ${ }^{26,27}$ and atlases ${ }^{28}$ at UHF. The normal anatomy of the M1 at UHF MR imaging consists of deeper cortical layers identified as a slight hypointense band immediately subjacent to a thinner superficial hyperintense layer. The subcortical hypointense line corresponding to U-fibers appears smooth, and the gray-white junction, poorly demarcated (Fig $1 A,-B$ ).

When the M1 anatomy differed from such configurations, and namely the M1 deeper layers were particularly thin ${ }^{23,29}$ and/or hypointense ${ }^{9,30}$ (Fig 1D, -E), images were judged as belonging to patients with ALS.

Sensitivity, specificity, positive predictive value, negative predictive value, and diagnostic accuracy in distinguishing patients and HS were calculated for each reader. Interobserver agreement was calculated with the Cohen $\kappa$ statistic. 

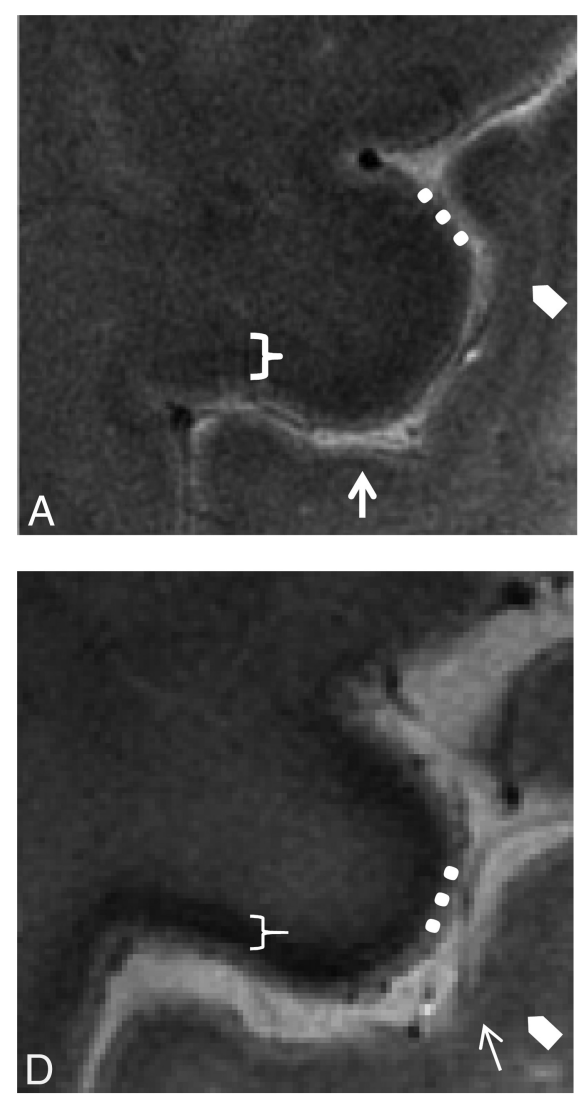
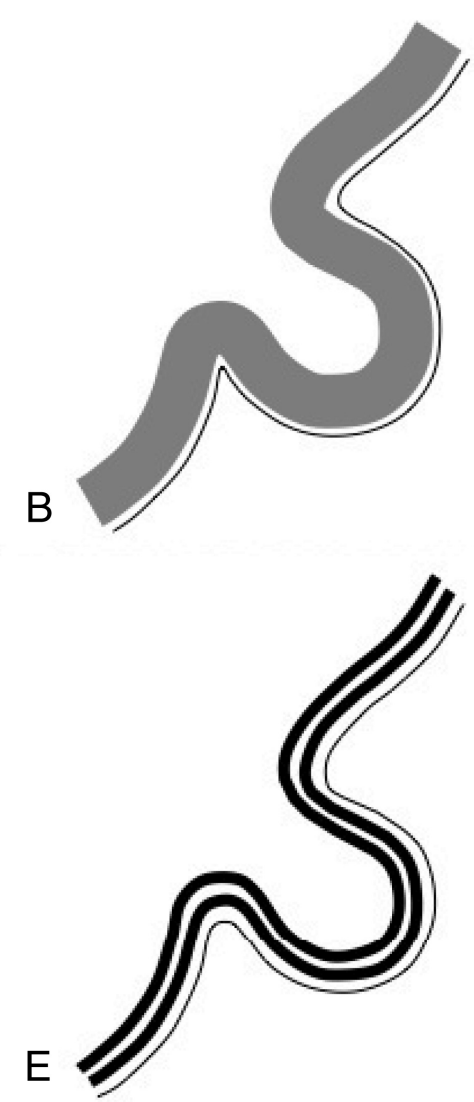
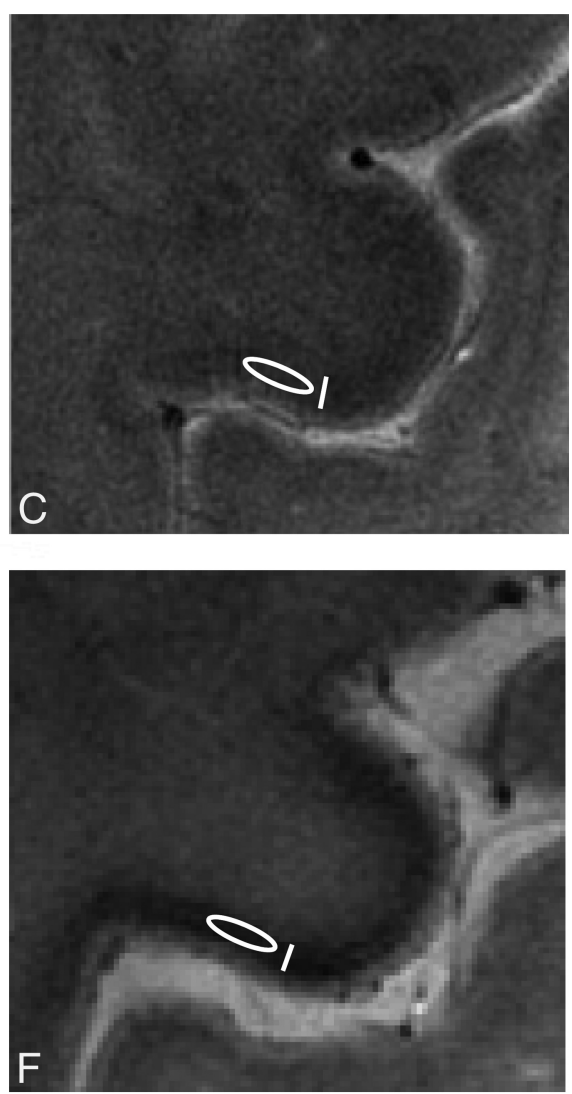

FIG 1. Normal anatomy. In vivo UHF high-resolution gradient recalled-echo T2* sequence acquisition of the pre- and postcentral gyri $(A)$ and its schematic representation $(B)$ in healthy subjects. The postcentral gyrus resembles the classic ex vivo UHF MR imaging appearance of the unimodal sensory cortices: a low signal intensity tier corresponding to heavily myelinated intracortical layer IV (external band of Baillarger) (arrows) and a subcortical hypointensity (arrowheads) corresponding to arcuate U-fibers demarcating the gray-white matter junction. ${ }^{56}$ The cortical ribbon of $\mathrm{Ml}$ (bracket) as the functional counterpart of Brodmann area $4^{35}$ is thicker than $\mathrm{Sl}^{57}$ because it is agranular ${ }^{36}$ and contains the giant Betz pyramidal cells. The superficial hyperintense layer in MR imaging (dots) is due to the lightly myelinated superficial layers relative to the more heavily myelinated deep layers. ${ }^{58} \mathrm{Ml}$ does not have an intermediate sharp hypointense line as in S1 but shows a more widespread slight hypointensity of the deeper cortical layer corresponding to its astriate myeloarchitecture. ${ }^{59,60}$ The deeper layers of M1 are not easily distinguished from the underlying white matter due to the heavily myelinated M1 cortex. ${ }^{32,58}$ ALS features. UHF high-resolution gradient recalledecho $\mathrm{T2}^{*}$ sequence acquisition of the pre- and postcentral gyri in a patient with ALS (D) and the corresponding schematic view (E). Beneath a preserved superficial cortical layer (dots), the deep layers in $\mathrm{Ml}$ are thinner and more hypointense (bracket) than those in healthy subjects and show an inconstant track appearance. The Ml signal hypointensity in ALS could be due to paramagnetic effects of the iron-containing microglia within the deep motor cortex. The method adopted for quantitative measurement of signal intensity and thickness in a healthy subject $(C)$ and in patients with ALS $(F)$ is reported. Quantitative assessments of the deep layers of M1 are obtained by drawing an oval ROI within them for the signal intensity measurement and a line with an electronic caliper for the thickness quantification.

Differences in UMN scores between correctly diagnosed and misdiagnosed patients were evaluated by a Mann-Whitney $U$ test.

Quantitative Assessment. For each cerebral hemisphere, thickness and signal intensity of the deeper layers of the M1 were measured in 4 anatomic regions corresponding to the Penfield's areas of foot, leg, hand, and face (Fig $1 C,-F) .{ }^{31}$ Signal intensities were measured by using oval ROIs of $4 \mathrm{~mm}^{2}$ and were normalized with respect to those of the superficial cerebral cortex of the left precuneus. Measurement of cortical thickness was obtained by tracing, with an electronic caliper, a line encompassing the deep layer of the M1. The measurements of signal intensity and cortical thickness for each subject were then averaged to obtain mean values from both cerebral hemispheres.

Quantitative data of cortical thickness and the signal intensity of the M1 were compared between patients and HS by using a Mann-Whitney $U$ test. In the group of patients, the relationship between morphometric parameters (mean values of cortical thickness and signal intensity) and clinical scores (ALSFRS-R, Medical Research Council scale, disease duration, and DPR) and the electrophysiologic (central conduction time, cortical latency, cortical silent period) and laboratory (ferric reducing ability of plasma, advanced oxidation protein products, plasma thiols) data was evaluated by the Spearman rank correlation coefficient. Cortical thickness and signal intensity of the M1 for each Penfield's area of hand, leg, and foot were correlated to the correspondent UMN score by using the Spearman rank correlation coefficient.

Using the median of DPR as a cutoff, we divided patients on the basis of the progression rate into 2 groups: "faster" and "slower." A Mann-Whitney $U$ test was applied to investigate differences in morphometric parameters between the 2 groups.

\section{RESULTS}

Four patients and 1 healthy control subject were excluded from the analysis due to the presence of severe motion artifacts. 

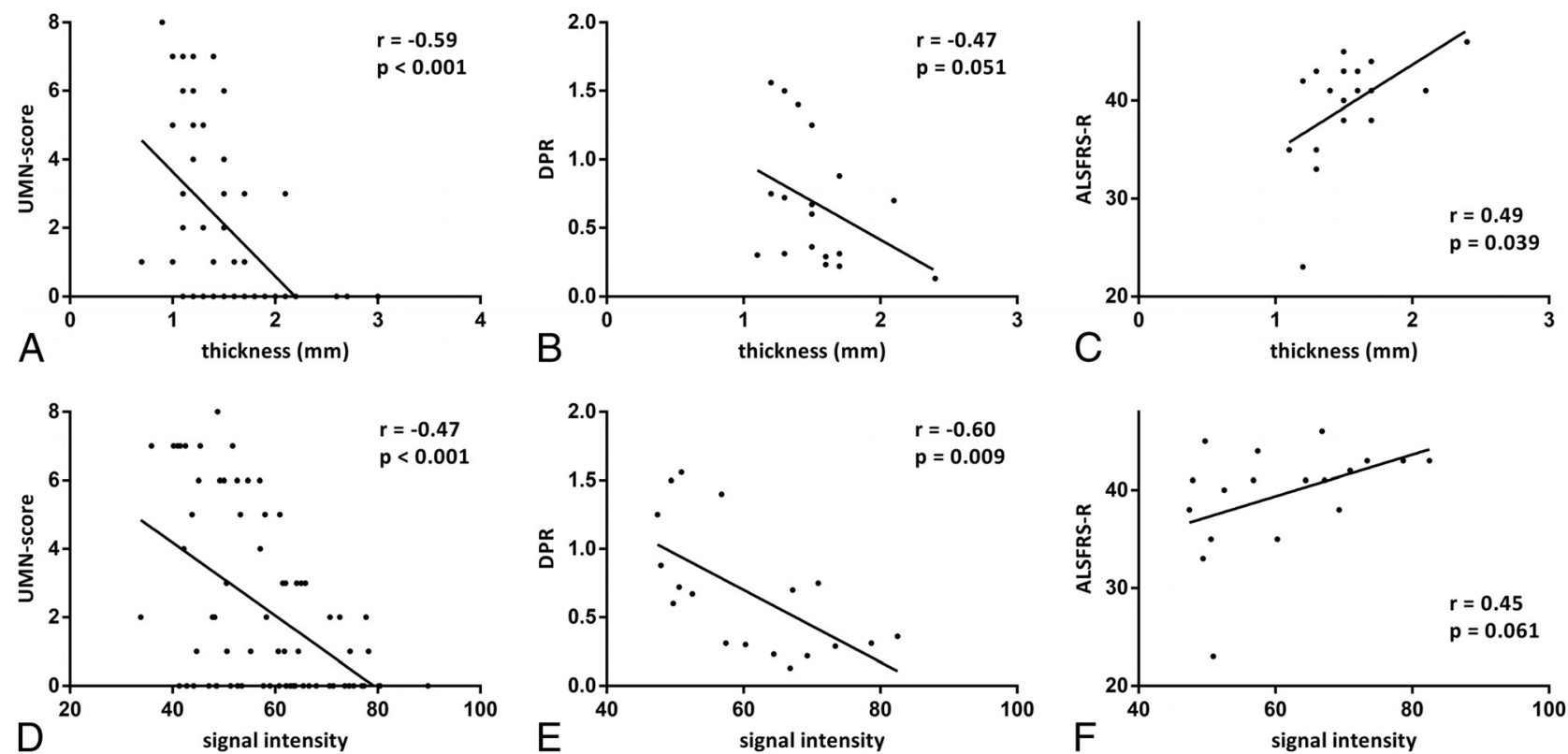

FIG 2. Correlations in patients with ALS between morphometric parameters (thickness and signal intensity of deeper layers of M1) and clinical scores (UMN score, DPR, and ALSFRS-R). The UMN score ranges from zero to 8 because it refers to a single limb and not to the overall evaluation. Correlations between morphometric parameters and UMN score were calculated by taking into account the clinical score of each limb of every patient and signal intensity and thickness of the corresponding areas of M1.

In the remaining 18 patients, the mean values were $40 \pm 5$ for ALSFRS-R, $9 \pm 10$ for the UMN score, $118 \pm 13$ for the Medical Research Council scale, $16 \pm 12$ for disease duration, and $0.68 \pm$ 0.47 for DPR.

\section{Visual Inspection and Subjective Assessment}

At visual inspection, reader 1 detected hypointensity and thinning of the deeper layers of the M1 in 12 of 18 patients with ALS and in 3 of 13 HS. Sensitivity, specificity, positive predictive value, negative predictive value, and diagnostic accuracy in distinguishing patients and HS on the basis of morphologic criteria were $67 \%$, $77 \%, 80 \%, 63 \%$, and $71 \%$, respectively.

Reader 2 detected hypointensity and thinning of the deeper layers of the M1 in 9 of 18 patients with ALS and in zero of $13 \mathrm{HS}$. Sensitivity, specificity, positive predictive value, negative predictive value, and diagnostic accuracy in distinguishing patients and HS on the basis of morphologic criteria were 50\%, 100\%, 100\%, $59 \%$, and $71 \%$, respectively.

The Interobserver agreement was good (0.61, Cohen $\kappa$ statistic).

On the basis of both readings, the UMN score was significantly higher $(P=.003$ and $P=.028$, respectively) in correctly diagnosed patients ( $13 \pm 10$ and $14 \pm 10$, respectively) than in misdiagnosed ones ( $1 \pm 1$ and $4 \pm 8$, respectively) (On-line Fig $1 A,-B$ and On-line Tables 3-6).

Also, the DPR was higher on the basis of both readings ( $P=$ .019 and $P=.066$, respectively) in correctly diagnosed patients $(0.85 \pm 0.48$ and $0.87 \pm 0.49$, respectively) than in misdiagnosed ones $(0.33 \pm 0.20$ and $0.48 \pm 0.38$, respectively).

\section{Quantitative Assessment}

Cortical thickness was significantly $(P<.001)$ lower in patients $($ mean value $=1.5 \mathrm{~mm})$ than in $\mathrm{HS}($ mean value $=2 \mathrm{~mm})$
(On-line Fig 1C) and showed a moderate correlation with the UMN score $(r=-0.59 ; P<.001)$ (Fig $2 A)$. Cortical thickness had a weaker correlation with DPR $(r=-0.47 ; P=.051)$ and ALSFRS-R $(r=0.49 ; P=.039)$ (Fig $2 B,-C)$.

Signal intensity did not differ between patients with ALS and HS (On-line Fig $1 D)$ but correlated with UMN score $(r=-0.47$; $P<.001)$, DPR $(r=-0.60 ; P=.009)$, and ALSFRS-R $(r=0.45$; $P=.061)($ Fig $2 D-F)$.

Signal intensity in the subgroup of patients with faster DPR was significantly lower than that in the slower DPR subgroup $(P=$ $.024)$, while no significant difference in cortical thickness was found between subgroups of patients (On-line Fig 2).

No significant correlations were found between morphometric parameters and either motor-evoked potential indices (central motor conduction time and cortical silent period) or the ferricreducing ability of plasma, advanced oxidation protein products, and thiols.

\section{DISCUSSION}

\section{UHF MR Signal in M1 of Controls and Patients with ALS}

UHF MR imaging allows an in vivo evaluation of the inner structure of the cerebral motor cortex of patients with ALS and controls. The gradient recalled-echo $\mathrm{T}^{*}$ sequence at $7 \mathrm{~T}$ provides information on the architectural organization of the human cortex in vivo, ${ }^{32}$ due to the iron and myelin contribution to $\mathrm{T}^{*}$ contrast. ${ }^{26}$ Because myelin and iron in the form of ferritin are strongly co-localized in the intracortical myelinated fibers, ${ }^{33}$ the MR signals across the cortical gray matter reflect myelin content and myeloarchitecture. ${ }^{34}$ The normal anatomy of the M1 (Brodmann area 4$)^{35}$ at UHF depends on its peculiar architecture: The large cortical thickness, inconspicuous lamination pattern, low cell density, and the absence of a clear boundary between layer VI 
and white matter ${ }^{36}$ correspond to the MR imaging findings of the motor cortex as shown in Fig $1 A,-B$.

In patients with ALS, in accordance with previous ex vivo UHF images of the affected cerebral cortices, ${ }^{9}$ we revealed a rim of signal hypointensity with an inconstant track appearance beneath a preserved superficial hyperintense cortical layer (Fig $1 D,-E$ ).

The decreased signal intensity of the motor cortex on $\mathrm{T}^{*}$ weighted images in patients with ALS may represent ferritin because at postmortem examination, the precentral cortex showed intensely stained microglia and macrophages after antiferritin antibody staining. ${ }^{13}$ Until now, cortical hypointensity in vivo seemed to involve the motor cortex in a full-thickness fashion at both conventional ${ }^{37}$ and $\mathrm{UHF}^{9} \mathrm{MR}$ imaging. Our targeted UHF MR imaging high-resolution study, as well as the ex vivo UHF imaging, demonstrated that in patients with ALS, the signal hypointensity is confined to the deeper layers of the cerebral cortex, the same structures in which several studies have shown an increased number of microglial cells resulting from local proliferation of resident microglia. ${ }^{38}$

PET with radioligand-binding biomarkers of activated microglia revealed that areas with the highest microglial activation in patients with ALS were the motor cortices, ${ }^{39}$ thus corresponding to the distribution of signal changes and atrophy that we have detected in our group of patients.

\section{Cortical Thickness in the M1 of Patients with ALS}

Cortical atrophy in ALS has been revealed in several voxel-based morphometry works ${ }^{40-42}$ by manual or automated measurements of the cortical thickness and has been interpreted as a structural surrogate of UMN degeneration. ${ }^{23}$ In particular, the regional grade of atrophy in different areas of M1 corresponds to a somatotopic functional disability supporting the concepts of cortical focality and motor phenotype heterogeneity. ${ }^{43}$ In line with previous results, our data confirmed the thinning of the M1 in patients with ALS and the correlation between the cortical atrophy and the UMN burden, but we observed that the alteration is confined to the deeper cortical layers rather than the full-thickness cortex. Moreover, cortical atrophy and signal hypointensity of the M1 in patients with ALS are in line, respectively, with the reduction of $\mathrm{N}$-acetylaspartate and the increase of myo-inositol ${ }^{44}$ as an expression of the neurodegenerative phenomena and gliosis.

\section{MR Imaging of M1: Biomarker for Diagnosis or Prognosis}

Several conventional MR imaging studies subjectively evaluated the cortical morphology and signal changes in patients with ALS. ${ }^{37,45-49}$ These studies using full-thickness measures of cortical signal changes were limited by low specificity because similar findings are age-related and can also be detected in subjects without ALS. ${ }^{50}$ Although our approach permitted the evaluation of the inner structure of the cerebral motor cortex, the diagnostic accuracy (71\%) and the sensitivity (67\% and 50\% for reader 1 and reader 2, respectively) of M1 morphologic changes remain unsatisfactory.

Unlike electrophysiologic data, in which a correlation with UMN impairment has never been demonstrated, ${ }^{51}$ in our study, the quantitative analysis showed that increased image hypointensity and the atrophic deep motor cortex both correspond to greater UMN involvement. The correlation between the signal intensity and the UMN score and the fact that the UMN score was significantly higher in correctly diagnosed patients than in misdiagnosed ones support the hypothesis that hypointensity is a marker of UMN degeneration rather than of ALS.

This relationship influences the diagnostic accuracy of MR imaging, which remains modest because the correct diagnosis of ALS based on cortical signal changes depends on the amount of UMN impairment in sampled patients. The variable impairment of UMNs in ALS explains why decreased signal intensity in ALS has been reported at a variable extent, ranging from $93 \%{ }^{37}$ to $30 \% .^{13}$

The cortical signal intensity correlates with DPR and could constitute a prognostic marker of the disease. Although we interpret signal intensity as an expression of activated microglia, we do not know the pathologic mechanism that regulates the disease progression in our patients.

Translational research in mutant SOD1 transgenic mice shows that microglial cells become activated before motor neurons disappear and well before clinical disease onset. ${ }^{52}$ Moreover SOD mutant levels in microglia regulate the rate of disease progression. ${ }^{53}$ The correlation between cortical signal hypointensity as a presumptive marker of activated microglia and DPR could constitute the basis of a longitudinal study of microgliosis in patients with ALS, widening the pathogenic scenario of the causes of this disease and offering novel targets for therapeutic development. To understand whether the neuroinflammatory reaction could be a therapeutic target in ALS, a reliable biomarker able to investigate and monitor the neuroinflammatory response to motor-neuron degeneration with time would be desirable. Besides laboratory inflammatory markers in the $\mathrm{CSF}^{54}$ and PET studies by using microglial ligands, high-resolution UHF MR imaging might provide alternative relevant information on neuroinflammation.

In ALS, biomarkers of disease or prognosis would be paramount for patient management and therapeutic implications. ${ }^{5}$ Advanced neuroimaging techniques provide an opportunity to assess disease pathophysiology and promise new biomarkers. ${ }^{55}$ The introduction of the UHF MR imaging of the cerebral cortex in evaluating patients with ALS could be an adjunctive tool in a multimodal approach to the research of biomarkers. ${ }^{5}$

The main limitation of the present study is the small sample of patients, which affects the statistical power. A further limitation is the impossibility of enrolling patients with advanced disease for logistic reasons related to their disability, which would probably have provided information on the course of the disease.

\section{CONCLUSIONS}

The combined high spatial resolution and sensitivity to paramagnetic substances of 7T MR imaging demonstrate in vivo signal changes of the cerebral motor cortex that resemble the distribution of activated microglia within the cortex of patients with ALS. Reduced cortical thickness and signal hypointensity of the M1 deep layers could constitute a marker of UMN impairment in patients with ALS. Further studies with a larger sample of patients would be desirable to confirm the UHF MR imaging results in motor neuron disorders.

AJNR Am J Neuroradiol 37:455-61 Mar 2016 www.ajnr.org 
Disclosures: Ilaria Pesaresi-RELATED: Grant: Ministry of Health.* Gabriele Siciliano_UNRELATED: Board Membership: Baxter International, Comments: clinical trial board membership; Expert Testimony: CSL Behring, ${ }^{*}$ Comments: therapeutic trial testimony; Payment for Lectures (including service on Speakers Bureaus): Baxter International, Grunenthal, Grifols; Payment for Manuscript Preparation: Baxter International; Payment for Development of Educational Presentations: Baxter International; Travel/Accommodations/Meeting Expenses Unrelated to Activities Listed: Kedrion, CSL Behring, Comments: meeting expenses. *Money paid to the institution.

\section{REFERENCES}

1. Strong M, Rosenfeld J. Amyotrophic lateral sclerosis: a review of current concepts. Amyotroph Lateral Scler Other Motor Neuron Disord 2003;4:136-43 CrossRef Medline

2. Claus D, Brunhölzl C, Kerling FP, et al. Transcranial magnetic stimulation as diagnostic and prognostic test in amyotrophic lateral sclerosis. J Neurol Sci 1995;129(suppl):30-34 CrossRef Medline

3. de Carvalho M, Dengler R, Eisen A, et al. Electrodiagnostic criteria for diagnosis of ALS. Clin Neurophysiol 2008;119:497-503 CrossRef Medline

4. Vucic S, Kiernan MC. Utility of transcranial magnetic stimulation in delineating amyotrophic lateral sclerosis pathophysiology. Handb Clin Neurol 2013;116:561-75 CrossRef Medline

5. Chiò A, Pagani M, Agosta F, et al. Neuroimaging in amyotrophic lateral sclerosis: insights into structural and functional changes. Lancet Neurol 2014;13:1228-40 CrossRef Medline

6. Ince PG, Evans J, Knopp M, et al. Corticospinal tract degeneration in the progressive muscular atrophy variant of ALS. Neurology 2003; 60:1252-58 CrossRef Medline

7. Philips T, Robberecht W. Neuroinflammation in amyotrophic lateral sclerosis: role of glial activation in motor neuron disease. Lancet Neurol 2011;10:253-63 CrossRef Medline

8. Turner MR, Cagnin A, Turkheimer FE, et al. Evidence of widespread cerebral microglial activation in amyotrophic lateral sclerosis: an [11C](R)-PK11195 positron emission tomography study. Neurobiol Dis 2004;15:601-09 CrossRef Medline

9. Kwan JY, Jeong SY, Van Gelderen P, et al. Iron accumulation in deep cortical layers accounts for MRI signal abnormalities in ALS: correlating 7 Tesla MRI and pathology. PLoS One 2012;7:e35241 CrossRef Medline

10. Haacke EM, Mittal S, Wu Z, et al. Susceptibility-weighted imaging: technical aspects and clinical applications, part 1. AJNR Am J Neuroradiol 2009;30:19-30 Medline

11. Liu M, Habib C, Miao Y, et al. Measuring iron content with phase. In: Haacke EM, Reichenbach JR, eds. Susceptibility Weighted Imaging in MRI: Basic Concept and Clinical Applications. 10th ed. Hoboken: John Wiley \& Sons; 2011:369-401

12. Duyn JH. High-field MRI of brain iron. Methods Mol Biol 2011;711: 239-49 CrossRef Medline

13. Adachi Y, Sato N, Saito Y, et al. Usefulness of SWI for the detection of iron in the motor cortex in amyotrophic lateral sclerosis. J Neuroimaging 2015;25:443-51 CrossRef Medline

14. Fischl B. Estimating the location of Brodmann areas from cortical folding patterns using histology and ex vivo MRI. In: Geyer S, Turner R, eds. Microstructural Parcellation of the Human Cerebral Cortex: From Brodmann's Post-Mortem Map to in Vivo Mapping with High-Field Magnetic Resonance Imaging. Berlin: Springer-Verlag; 2013:129-56

15. Brooks BR, Miller RG, Swash M, et al; World Federation of Neurology Research Group on Motor Neuron Disease. El Escorial revisited: revised criteria for the diagnosis of amyotrophic lateral sclerosis. Amyotroph Lateral Scler Other Motor Neuron Disord 2000;1:293-99 CrossRef Medline

16. Folstein MF, Folstein SE, McHugh PR. "Mini-mental state": a practical method for grading the cognitive state of patients for the clinician. J Psychiatr Res 1975;12:189-98 CrossRef Medline

17. Appollonio I, Leone $\mathrm{M}$, Isella $\mathrm{V}$, et al. The frontal assessment battery (FAB): normative values in an Italian population sample. Neurol Sci 2005;26:108-16 CrossRef Medline
18. Siciliano G, Piazza S, Carlesi C, et al. Antioxidant capacity and protein oxidation in cerebrospinal fluid of amyotrophic lateral sclerosis. J Neurol 2007;254:575-80 CrossRef Medline

19. Cedarbaum JM, Stambler N, Malta E, et al. The ALSFRS-R: a revised ALS functional rating scale that incorporates assessments of respiratory function: BDNF ALS Study Group (Phase III). J Neurol Sci 1999;169:13-21 CrossRef Medline

20. Florence JM, Pandya S, King WM, et al. Intrarater reliability of manual muscle test (Medical Research Council scale) grades in Duchenne's muscular dystrophy. Phys Ther 1992;72:115-22; discussion 122-26 Medline

21. Ashworth B. Preliminary trial of carisoprodol in multiple sclerosis. Practitioner 1964;192:540-42 Medline

22. Woo JH, Wang S, Melhem ER, et al. Linear associations between clinically assessed upper motor neuron disease and diffusion tensor imaging metrics in amyotrophic lateral sclerosis. PLoS One 2014;9:e105753 CrossRef Medline

23. Walhout R, Westeneng HJ, Verstraete E, et al. Cortical thickness in ALS: towards a marker for upper motor neuron involvement. J Neurol Neurosurg Psychiatry 2015;86:288-94 CrossRef Medline

24. Yousry TA, Schmid UD, Alkadhi H, et al. Localization of the motor hand area to a knob on the precentral gyrus: a new landmark. Brain 1997;120:141-57 CrossRef Medline

25. Zilles K. Amunts K. Architecture of the cerebral cortex. In: Mai JK, Paxinos G, eds. The Human Nervous System. 3rd ed. London: Elsevier; 2012:836-95

26. Duyn JH, van Gelderen P, Li TQ, et al. High-field MRI of brain cortical substructure based on signal phase. Proc Natl Acad Sci US A 2007;104:11796-801 CrossRef Medline

27. Geyer S, Weiss M, Reimann K, et al. Microstructural parcellation of the human cerebral cortex: from Brodmann's post-mortem map to in vivo mapping with high-field magnetic resonance imaging. Front Hum Neurosci 2011;5:19 CrossRef Medline

28. Geyer S, Turner R. Microstructural Parcellation of the Human Cerebral Cortex: From Brodmann's Post-Mortem Map to in Vivo Mapping with High-Field Magnetic Resonance Imaging. Berlin: Springer-Verlag; 2013

29. Verstraete E, Veldink JH, Hendrikse J, et al. Structural MRI reveals cortical thinning in amyotrophic lateral sclerosis. J Neurol Neurosurg Psychiatry 2012;83:383-88 CrossRef Medline

30. Ignjatović A, Stević Z, Lavrnić S, et al. Brain iron MRI: a biomarker for amyotrophic lateral sclerosis. J Magn Reson Imaging 2013;38: 1472-79 CrossRef Medline

31. Penfield W, Rasmussen T. The Cerebral Cortex of Man: A Clinical Study of Localization of Function. New York: Macmillan; 1950

32. Cohen-Adad J, Polimeni JR, Helmer KG, et al. $\mathbf{T}_{2}{ }^{*}$ mapping and $\mathbf{B}_{\mathbf{0}}$ orientation-dependence at $7 \mathrm{~T}$ reveal cyto- and myeloarchitecture organization of the human cortex. Neuroimage 2012;60:1006-14 CrossRef Medline

33. Fukunaga M, Li TQ, van Gelderen P, et al. Layer-specific variation of iron content in cerebral cortex as a source of MRI contrast. Proc Nat Acad Sci U S A 2010;107:3834-39 CrossRef

34. Turner R. MRI methods for in-vivo cortical parcellation. In: Geyer S, Turner R, eds. Microstructural Parcellation of the Human Cerebral Cortex: From Brodmann's Post-Mortem Map to in Vivo Mapping with High-Field Magnetic Resonance Imaging. Berlin: Springer-Verlag; 2013:197-220

35. Brodmann K. Vergleichende Lokalisationslehre der Grosshirnrinde. Leipzig: Barth; 1909

36. Brodmann K. Beiträge zur histologischen Lokalisation der Grosshirnrinde: Erste Mitteilung-Die Regio Rolandica. J Psychol Neurol 1903;2:79-107

37. Oba H, Araki T, Ohtomo K, et al. Amyotrophic lateral sclerosis: T2 shortening in motor cortex at MR imaging. Radiology 1993;189: 843-46 CrossRef Medline

38. Gowing G, Philips T, Van Wijmeersch B, et al. Ablation of proliferating microglia does not affect motor neuron degeneration in 
amyotrophic lateral sclerosis caused by mutant superoxide dismutase. J Neurosci 2008;28:10234-44 CrossRef Medline

39. Corcia P, Tauber C, Vercoullie J, et al. Molecular imaging of microglial activation in amyotrophic lateral sclerosis. PLoS One 2012;7: e52941 CrossRef Medline

40. Agosta F, Pagani E, Rocca MA, et al. Voxel-based morphometry study of brain volumetry and diffusivity in amyotrophic lateral sclerosis patients with mild disability. Hum Brain Mapp 2007;28: 1430-38 CrossRef Medline

41. Mezzapesa DM, Ceccarelli A, Dicuonzo F, et al. Whole-brain and regional brain atrophy in amyotrophic lateral sclerosis. AJNR Am J Neuroradiol 2007;28:255-59 Medline

42. Cosottini M, Pesaresi I, Piazza S, et al. Structural and functional evaluation of cortical motor areas in amyotrophic lateral sclerosis. Exp Neurol 2012;234:169-80 CrossRef Medline

43. Bede P, Bokde A, Elamin M, et al. Grey matter correlates of clinical variables in amyotrophic lateral sclerosis (ALS): a neuroimaging study of ALS motor phenotype heterogeneity and cortical focality. J Neurol Neurosurg Psychiatry 2013;84:766-73 CrossRef Medline

44. Foerster BR, Pomper MG, Callaghan BC, et al. An imbalance between excitatory and inhibitory neurotransmitters in amyotrophic lateral sclerosis revealed by use of 3-T proton magnetic resonance spectroscopy. JAMA Neurol 2013;70:1009-16 CrossRef Medline

45. Goodin DS, Rowley HA, Olney RK. Magnetic resonance imaging in amyotrophic lateral sclerosis. Ann Neurol 1988;23:418-20 CrossRef Medline

46. Ishikawa K, Nagura $\mathrm{H}$, Yokota $\mathrm{T}$, et al. Signal loss in the motor cortex on magnetic resonance images in amyotrophic lateral sclerosis. Ann Neurol 1993;33:218-22 CrossRef Medline

47. Cheung G, Gawel MJ, Cooper PW, et al. Amyotrophic lateral sclerosis: correlation of clinical and MR imaging findings. Radiology 1995;194:263-70 CrossRef Medline

48. Thorpe JW, Moseley IF, Hawkes CH, et al. Brain and spinal cord MRI in motor neuron disease. J Neurol Neurosurg Psychiatry 1996;61: 314-17 CrossRef Medline

49. Hecht MJ, Fellner F, Fellner C, et al. Hyperintense and hypointense
MRI signals of the precentral gyrus and corticospinal tract in ALS: a follow-up examination including FLAIR images. J Neurol Sci 2002; 199:59-65 CrossRef Medline

50. Cosottini M, Cecchi P, Piazza S, et al. Mapping cortical degeneration in ALS with magnetization transfer ratio and voxel-based morphometry. PLoS One 2013;8:e68279 CrossRef Medline

51. Yokota T, Yoshino A, Inaba A, et al. Double cortical stimulation in amyotrophic lateral sclerosis. J Neurol Neurosurg Psychiatry 1996;61: 596-600 CrossRef Medline

52. Hall ED, Oostveen JA, Gurney ME. Relationship of microglial and astrocytic activation to disease onset and progression in a transgenic model of familial ALS. Glia 1998;23:249-56 CrossRef Medline

53. Boillée S, Yamanaka K, Lobsiger CS, et al. Onset and progression in inherited ALS determined by motor neurons and microglia. Science 2006;312:1389-92 CrossRef Medline

54. Mitchell RM, Freeman WM, Randazzo WT, et al. A CSF biomarker panel for identification of patients with amyotrophic lateral sclerosis. Neurology 2009;72:14-19 CrossRef Medline

55. Foerster BR, Welsh RC, Feldman EL. 25 years of neuroimaging in amyotrophic lateral sclerosis. Nat Rev Neurol 2013;9:513-24 CrossRef Medline

56. Fatterpekar GM, Naidich TP, Delman BN, et al. Cytoarchitecture of the human cerebral cortex: MR microscopy of excised specimens at 9.4 Tesla. AJNR Am J Neuroradiol 2002;23:1313-21 Medline

57. Meyer J, Roychowdhury S, Russell EJ, et al. Location of the central sulcus via cortical thickness of the precentral and postcentral gyri on MR. AJNR Am J Neuroradiol 1996;17:1699-706 Medline

58. Glasser MF, Van Essen DC. Mapping human cortical areas in vivo based on myelin content as revealed by T1- and T2-weighted MRI. J Neurosci 2011;31:11597-616 CrossRef Medline

59. Vogt O. Die myeloarchitektonische Felderung des Menschlichen Stirnhirns. J Psychol Neurol 1910;15:221-32

60. Braitenberg V. Die Gliederung der Stirnhirnrinde auf Grund ihres Markfaserbaus (Myeloarchitektonik). In: Rehwald E, ed. Das Hirntrauma. Stuttgart: Thieme; 1956:183-203 